\title{
Immobilization of Mycelial Pellets from Liquid Spawn of Oyster Mushroom Based on Carrier Adsorption
}

\author{
Lanqing Wang ${ }^{1}$, Yinfeng $\mathrm{Li}^{1}$, Dehai $\mathrm{Liu}^{2}$, Chaohui Zhang ${ }^{1}$, \\ Yuancheng $\mathrm{Qi}^{1}$, Yuqian Gao ${ }^{1}$, Jinwen Shen ${ }^{1}$, and Liyou Qiu ${ }^{1,3}$
}

AdDitional Index wORDs. enzyme, respiration intensity, cultivation, Pleurotus ostreatus

SUMMARY. We investigated a practical method for immobilizing liquid spawn of oyster mushroom (Pleurotus ostreatus) to prolong the storage time and provide convenient transportation of liquid spawn of edible mushrooms. The method was based on the mycelial pellets of liquid spawn adsorbed in carriers. Selected carriers were similar to cultivation substrates, and the best carrier was a mixture of cottonseed hull, corn core, and wheat bran with a ratio of 4.5:4.5:1 by weight. Immobilized spawn were prepared by mixing the pellets from liquid spawn with carriers using a ratio of $1: 8$ by weight. Within the first 15 days of storage at 20-25 ${ }^{\circ} \mathrm{C}$, the immobilized spawn grew strongly, respiration intensity and cellulase activities rose rapidly, and the count and brightness of the isozyme bands of esterase, peroxidase, and polyphenol oxidase increased remarkably as well. From days $\mathbf{3 0}$ to 60 , the cellulase activities fell and the brightness of the peroxidase and polyphenol oxidase bands gradually decreased, whereas the respiration intensity and the band count of esterase and peroxidase remained constant. After 60 days, the cultivated characteristics of the immobilized spawn were same as the fresh conventional solid cottonseed hull spawn. The results showed that immobilized spawn on the basis of the mycelial pellets of liquid spawn adsorbed in carrier can be used to extend the storage time and simplify transportation of liquid spawn of edible mushroom.

$\mathrm{O}$ yster mushroom is one of the most widely cultivated edible mushrooms in the world (Chang, 1999); it is also used in medicine (El-Fakharany et al., 2010; Gern et al., 2008), environmental remediation (Rodríguez Pérez et al., 2008; Yan et al., 2009), and biofuel (OkamuraMatsui et al., 2003). Like most other edible mushrooms, its spawn for cultivation is in solid state, which is composed of manure-grass, sawdust, wood block, branch wood, and grain. Solid spawns are universally used by mushroom growers throughout the world because they can be made with simple equipments and techniques, but the process also needs large space and long incubation period. Additionally, age of the mycelia in different position of solid spawn is rather different; those near the inoculum age faster. Consequently, the growth rate of the mycelia and the time course of sporophore

${ }^{1}$ College of Life Sciences, Henan Agricultural University, 95 Wenhua Road, Zhengzhou 450002, China.

${ }^{2}$ Institute of Biology, Henan Academy of Sciences, 28 Huayuan Road, Zhengzhou 450008, China.

${ }^{3}$ Corresponding author. E-mail: qliyou@henau.edu.cn. development vary considerably (Liu et al., 2009).

Since the first report on production of commercial meadow mushroom [Agaricus campestris (Humfeld, 1948)] producing mycelia in submerged culture has been widely practiced (Zhong and Tang, 2004). In 1966, an American attained the first patent of liquid mushroom spawn (Laniece, 1966). Up to now, liquid spawn is widely used in the cultivation of many mushrooms, including button mushroom [Agaricus bisporus (Friel and McLoughlin, 2000)], oyster mushroom (Laniece, 1966; Silveira et al., 2008), shiitake [Lentinus edodes (Kirchhoff and Lelley, 1991; Pellinen et al., 1987)], brazilian oyster mushroom [Pleurotus ostreatorosens (Rosado et al., 2002)], paris mushroom (A. bisporus var. hortensis), wood blewit (Tricholoma nudum), garden morel (Morchella hortensis), yellow morel (Morchella esculenta), and chanterelle [Cantharellus cibarius (Laniece, 1966)]. Compared with the solid spawns, there are numerous advantages of adapting the liquid culture technique, such as improved automation in the spawn plant, more uniform distribution of the inoculum in the substrate (Eyal, 1991), producing large amounts of mycelia quickly at any time of the year, a more homogeneous fungal growth, lower cost (Rosado et al., 2002), early fruiting (Kawai et al., 1995), and high fruit body yield (Kirchhoff and Lelley, 1991).

On the other hand, it is difficult to store and transport liquid spawn and its residual nutrients may cause contamination; in addition, liquid spawns of several mushrooms could not colonize on some cultivation substrates (Friel and McLoughlin , 1999; Leatham and Griffin, 1984). These problems limit its further application in the mushroom industry. In this study, we investigate an immobilization method for liquid spawn of oyster mushroom to achieve longer storage time and convenient transportation.

\section{Materials and methods}

LIQUID SPAWN AND SOLID SPAWN PREPARATION. Oyster mushroom TD300, a commercially cultivated strain in China, was chosen for our experiments. The media used were potato dextrose agar (PDA), potato dextrose broth (PDB), liquid spawn medium (LSM), and cottonseed hull cultivated medium (CCM). LSM was composed of $10 \mathrm{~g}$ corn flour, $20 \mathrm{~g}$ soybean meal powder, $30 \mathrm{~g}$ sucrose, $5 \mathrm{~g}$ yeast extract, $1 \mathrm{~g}$ potassium dihydrogen phosphate $\left(\mathrm{KH}_{2} \mathrm{PO}_{4}\right), 0.5 \mathrm{~g}$ magnesium sulfate heptahydrate $\left(\mathrm{MgSO}_{4} \cdot 7 \mathrm{H}_{2} \mathrm{O}\right), 2 \mathrm{~g}$ calcium carbonate $\left(\mathrm{CaCO}_{3}\right)$, and $1 \mathrm{~L}$

\begin{tabular}{llll}
\hline $\begin{array}{l}\text { Units } \\
\begin{array}{l}\text { To convert U.S. to SI, } \\
\text { multiply by }\end{array}\end{array}$ & U.S. unit & SI unit & $\begin{array}{l}\text { To convert SI to U.S., } \\
\text { multiply by }\end{array}$ \\
\hline 29.5735 & $\mathrm{fl} \mathrm{oz}$ & $\mathrm{mL}$ & 0.0338 \\
1043.1756 & $\mathrm{fl} \mathrm{oz} / \mathrm{oz}$ & $\mu \mathrm{L} \cdot \mathrm{g}^{-1}$ & $9.5861 \times 10^{-4}$ \\
3.7854 & gal & $\mathrm{L}$ & 0.2642 \\
2.54 & inch $(\mathrm{es})$ & $\mathrm{cm}$ & 0.3937 \\
25.4 & inch $(\mathrm{es})$ & $\mathrm{mm}$ & 0.0394 \\
28.3495 & $\mathrm{oz}$ & $\mathrm{g}$ & 0.0353 \\
0.0069 & $\mathrm{psi}$ & $\mathrm{MPa}$ & 145.0377 \\
$\left({ }^{\circ} \mathrm{F}-32\right) \div 1.8$ & ${ }^{\circ} \mathrm{F}$ & ${ }^{\circ} \mathrm{C}$ & $\left(1.8 \times{ }^{\circ} \mathrm{C}\right)+32$ \\
& & &
\end{tabular}


tap water. CCM was a mixture of $100 \mathrm{~g}$ cottonseed hulls, $1 \mathrm{~g}$ lime, $1 \mathrm{~g}$ gypsum, and $110 \mathrm{~mL}$ tap water (Qiu et al., 2010). TD300 was stored on PDA slants at $4^{\circ} \mathrm{C}$ and was transferred every 2 months. Cultures were grown on PDA plates at $25^{\circ} \mathrm{C}$ for $7 \mathrm{~d}$. A $1-\mathrm{cm}^{-}$ diameter mycelial plug from the peripheral edge of a 7 -d-old colony was used for the production of liquid cultures. The fungus was cultivated in 150 $\mathrm{mL} \mathrm{PDB}$ in a 500 - $\mathrm{mL}$ flask at $25^{\circ} \mathrm{C}$ under $150 \mathrm{rpm}$ shaking (HZQ-Q shaking incubator with temperature; HDL, Harbin, China). After 7-8 d, the mycelia were cultivated up to the later log phase to produce an inoculum for liquid cultures in fermentor, which has a total volume of $40 \mathrm{~L}$ (BIOTECH-40JS; Baoxing, Shanghai, China). Twenty-eight liters of LSM was added in the fermentor and the amount of inoculum produced was $7.5 \%(\mathrm{v} / \mathrm{v})$. The culture conditions were cultivation temperature at $25{ }^{\circ} \mathrm{C}$, agitation speed at $160 \mathrm{rpm}$, pressure in fermenter at $0.04 \mathrm{MPa}$, and aeration rate at $0.7 \mathrm{~m}^{3} \cdot \mathrm{h}^{-1}$. The mycelia were cultivated for $96 \mathrm{~h}$, reaching the maximum biomass, and then harvested to prepare immobilized spawn. Conventional solid spawn was prepared as described (Qiu et al., 2010).

IMMOBILIZATION OF LIQUID SPAWN. Three immobilization carrier mixtures listed in Table 1 were tested. Each was blended with pellets of TD300 on a weight ratio of $1: 10$ to make immobilized spawns; as shown in Results and discussion, the mixture of cottonseed hull, corn core, and wheat bran at a ratio of 4.5:4.5:1 by weight was strongly favored. The corn core was milled to 18-20 mesh beforehand. The pellets of TD300 were collected from liquid spawn by centrifugation at $650 \mathrm{~g}$ for $5 \mathrm{~min}$ and then blended with sterilized carrier to prepare immobilized spawn in a sterile room; water content of immobilized carrier was adjusted to $65 \%$ before sterilization using tap water. The immobilized spawns were kept in plastic bags at $300 \mathrm{~g}$ per bag at $20-25^{\circ} \mathrm{C}$; the plastic bag is made of polypropylene, $12 \mathrm{~cm}$ wide, $24 \mathrm{~cm}$ long, and $0.04 \mathrm{~mm}$ thick.

Two grams of immobilized spawn were inoculated into one end of a plastic bag containing $300 \mathrm{~g} \mathrm{CCM}$ and then incubated at $25^{\circ} \mathrm{C}$ until the mycelia colonized the content of the bag to determine the lag phase and growth rate of immobilized spawn.
The duration from inoculation to the beginning of mycelial growth (i.e., the lag phase) was recorded. Starting with the steady growth of mycelia, the position of the advancing mycelial front was marked on the bag at 4-d interval to measure mycelial growth rate.

Experiments of basidiomata production were carried out using plastic bags containing 1000 g CCM. Five grams of immobilized spawn or solid spawn (as control) were inoculated into one end of a plastic bag and cultivated as described by Qiu et al. (2010). Biological efficiency (BE) was defined as the percentage of the fresh weight of harvested mushrooms over the dry weight of inoculated substrates.

Respiration intensity of immobilized spawn and solid spawn was determined using the small-skep method based on carbon dioxide $\left(\mathrm{CO}_{2}\right)$ absorption (Chinese Society of Plant Physiology, 1985). Cellulase activity, including filter paper activity (FPA) and carboxymethyl cellulase activity (CMCA), was determined by the method of Miller and his colleagues
(Miller, 1959; Miller et al., 1960). The enzyme activity was expressed in specific activity units defined as international units (IU) per gram dry weight of spawn (1 IU = quantity of enzyme required to produce $1 \mu \mathrm{mol}$ of glucose per minute under the assay conditions). The isozyme patterns of esterase, peroxidase, and polyphenol oxidase of immobilized spawn and solid spawn during storage were analyzed using polyacrylamide gel electrophoresis as described by Yan (1997).

The mean of five replicates was used in the result, except the basidiomata production experiment, which was performed with 20 replicates. Means were separated using Duncan's multiple range tests.

\section{Results and discussion}

Among the three tested carrier mixtures, the one composed of cottonseed hull, corn core, and wheat bran exhibited significantly lower lag phase $(P<0.01)$ and higher mycelial growth rate $(P<0.05)$ (Table 1$)$ and was selected for the experiments thereafter.

Table 1. The lag phase and growth rate of immobilized spawn of oyster mushroom TD300 in different carriers.

\begin{tabular}{lcc}
\hline $\begin{array}{l}\text { Immobilization } \\
\text { carriers }^{\mathrm{z}}\end{array}$ & $\begin{array}{c}\text { Lag phase } \\
{[\text { mean } \pm \text { SE }(\mathbf{h})]}\end{array}$ & $\begin{array}{c}\text { Mycelial growth rate } \\
{\left[\text { mean } \pm \text { SD }\left(\mathbf{c m} \cdot \mathbf{d}^{-1}\right)\right]^{\mathrm{y}}}\end{array}$ \\
\hline $\begin{array}{l}\text { cottonseed hull + bran }(\mathrm{w}: \mathrm{w}=9: 1) \\
\text { cottonseed hull + corn core + wheat bran }\end{array}$ & $52.8 \pm 3.4 \mathrm{~B}^{\mathrm{x}}$ & $0.46 \pm 0.09 \mathrm{~b}^{\mathrm{x}}$ \\
$\quad(\mathrm{w} / \mathrm{w} / \mathrm{w}=4.5: 4.5: 1)$ & $38.4 \pm 2.5 \mathrm{~A}$ & $0.51 \pm 0.03 \mathrm{a}$ \\
cottonseed hull + corn flour $(\mathrm{w}: \mathrm{w}=9: 1)$ & $53.4 \pm 4.4 \mathrm{~B}$ & $0.47 \pm 0.04 \mathrm{~b}$ \\
\hline
\end{tabular}

${ }^{\mathrm{z}} \mathrm{W}: \mathrm{w}$ is the ratio of carriers by weight.

$\mathrm{y} \mathrm{cm}=0.3937$ inch

${ }^{x}$ Means followed by the same lower and upper case letters are not significantly different by Duncan's multiple range test at $P<0.05$ and $P<0.01$, respectively.

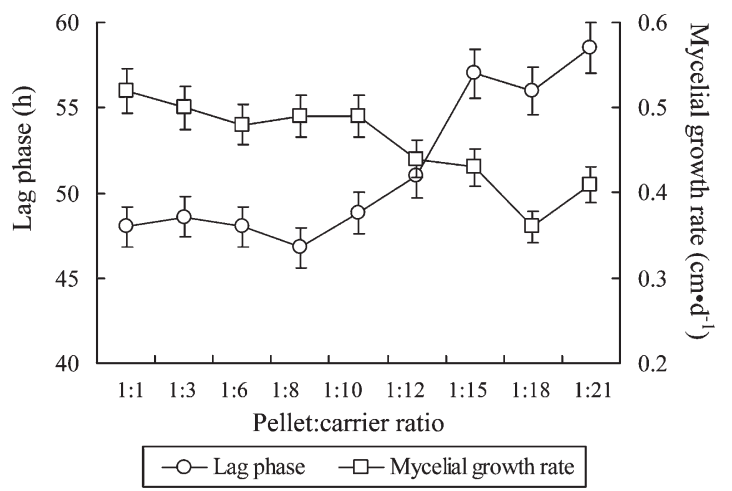

Fig. 1. Effect of the ratio between pellets and immobilized carrier of oyster mushroom TD300 (by weight) on lag phase and mycelial growth rate. The carrier is composed of cottonseed hull, corn core, and wheat bran. The ratio of pellets to immobilization carrier varied from $1: 1$ to $1: 21$ by weight. Bars indicate $S E$ of measurement; $1 \mathrm{~cm}=0.3937$ inch. 
The ratio between pellets and immobilization carrier varied from 1:1 to $1: 21$ by weight, and the lag phases of immobilized spawn growth displayed a "V"-shape change. The 1:8 ratio produced the shortest lag phase and a high mycelial growth rate (Fig. 1) and was used to prepare immobilized spawn.

To our knowledge, the changes in physiological and cultivated characteristics of mushroom spawn during storage have not been reported. During storage for the first $45 \mathrm{~d}$, the respiration intensity of immobilized spawn increased linearly, probably due to the gradualness in pellets' growth on the immobilization carrier. The activities of lignocellulolytic enzymes rose and mycelial biomass subsequently enlarged. Between days 45 and 60, the respiration intensified more rapidly (Fig. 2), likely because of the greater mycelial biomass; high respiration intensity was an indication of the high vigor of spawn.

CMCA and FPA of immobilized spawn surged from days 1 to 15 and then FPA fell back slightly, whereas CMCA reduced by $22.3 \%$ to $169.1 \%$ during days 30 to 60 (Fig. 3). A similar trend was observed in oyster mushroom Florida f6 during solid-state fermentation (Kerem et al., 1992); a partial explanation was that oyster mushroom had the higher selectivity for lignin degradation.

Three isozymograms of immobilized spawn, including esterase, peroxidase, and polyphenol oxidase, were analyzed during the 60 -d storage. The number of esterase isozyme bands on days $1,15,30$, and 60 were one, two, three, and six, respectively; the band of esterase isozymograms on day 60 was the same as that of fresh conventional solid spawn; the results suggested that

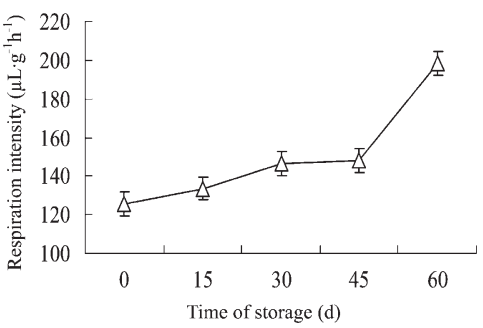

Fig. 2. Changes in respiration intensity of immobilized spawn oyster mushroom TD300 during storage at 20-25 ${ }^{\circ} \mathrm{C}\left(68.0-77.0^{\circ} \mathrm{F}\right)$. Bars indicate SE of measurement; $1 \mu \mathrm{L} \cdot \mathrm{g}^{-1}=9.5861 \times$ $10^{-4} \mathrm{fl} \mathrm{oz} / \mathrm{oz}$. pellets were steadily adapting and growing on immobilization carrier (Fig. 4A).

Peroxidase isozyme of immobilized spawn displayed one band on day 1 and two on day 15; the two bands were similar to that of fresh conventional solid spawn, but were wider and brighter, and gradually weakened thereafter; an additional light band appeared after day 30 (Fig. 4B). Polyphenol oxidase isozyme produced only one band on day 15 , same as the isozyme pattern of fresh conventional solid spawn (Fig. 4C). These results revealed that the vigor of immobilized spawn got lost gradually after $15 \mathrm{~d}$.

Immobilized spawn was inoculated into a plastic bag containing $1000 \mathrm{~g}$ CCM for $60 \mathrm{~d}$ to observe cultivation characteristics; its BE varied from $82.4 \%$ to $88.1 \%$. It took 49.2 to $63.1 \mathrm{~d}$ to reach full mycelia colonization and another 8.8 to $11.8 \mathrm{~d}$ for primordium initiation of immobilized spawn. The cultivation characteristics of immobilized spawn after $60 \mathrm{~d}$ did not significantly differ from those of fresh solid spawn used as control (Table 2); the results demonstrated that immobilized spawn could be stored for at least 2 months.

In agriculture, immobilization technique has been widely used in the preparation of inocula to improve its ecological competence (McLoughlin, 1994); a few studies on immobilized

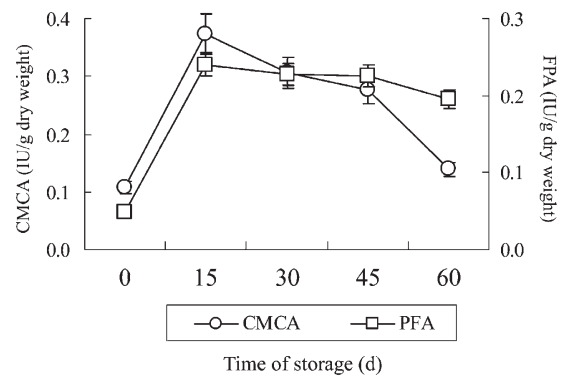

Fig. 3. Changes in cellulase activities of immobilized spawn during storage at 20-25 ${ }^{\circ} \mathrm{C}\left(68.0-77.0^{\circ} \mathrm{F}\right)$. Immobilized spawn was prepared by mixing pellets of TD300 and carriers (cottonseed hull + corn core + wheat bran) at a ratio of $1: 8$ by weight. The enzyme activity was expressed in units of specific activity defined as international units (IU) per gram dry weight of spawn (1 $\mathrm{IU}=$ the amount of enzyme required to produce $1 \mu \mathrm{mol}$ of glucose per minute under the assay conditions). Bars indicate SE of measurement; $1 \mathrm{IU} /$ $\mathrm{g}=28.3495 \mathrm{IU} / \mathrm{oz}$. CMCA, carboxymethyl cellulase activity; PFA, filter paper activity. spawn of edible mushroom have also been reported. In one study, immobilized alginate beads of button mushroom were prepared by entrapping liquid spawn with vermiculite, hygramer, and nourishment in sodium alginate; its performance was comparable to that of grain spawn in the shape and yield of fruit body (Rosado et al., 2002). However, Friel and McLoughlin (1999) reported that such a spawn, if without nourishment, could not survive in pasteurized compost and that the biomass levels were significantly lower than that of the conventional grain spawn; with the entrapment of both the mycelium and a nutrient source in the beads, the biomass levels were boosted by 3 -folds after cultivation in malt extract broth for $4 \mathrm{~d}$; at same biomass levels, coentrapped mycelial beads had more inocula points, a shorter adaptation (lag) period, and a higher growth rate in pasteurized compost than the conventional grain spawn.

Although spawn immobilization through the entrapment of alginate beads offers promising results, it is also complicated, time consuming, and

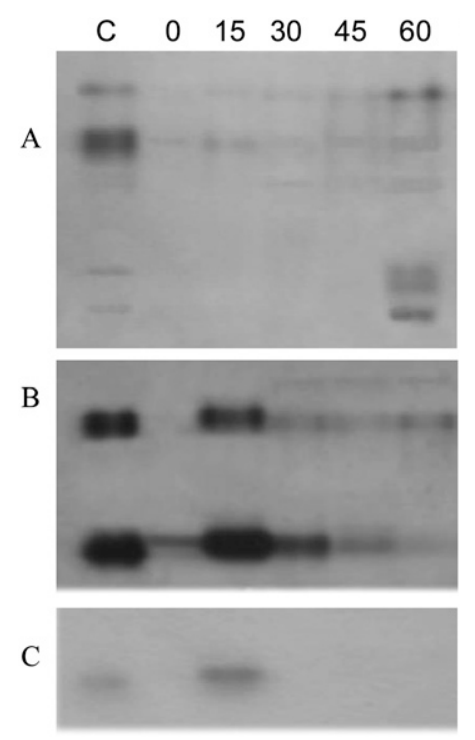

Fig. 4. Changes in isozyme patterns of immobilized spawn during storage at 20-25 ${ }^{\circ} \mathrm{C}\left(68.0-77.0^{\circ} \mathrm{F}\right)$. Immobilized spawn prepared by mixing pellets of TD300 and carriers (cottonseed hull + corn core + wheat bran) on a ratio of 1:8 by weight: (A) esterase, (B) peroxidase, and $(C)$ polyphenol oxidase. Lane $\mathbf{C}$ is conventional solid spawn before storage. Lanes $0,15,30$, 45 , and 60 are immobilized spawn stored for $0,15,30,45$, and $60 \mathrm{~d}$, respectively. 
Table 2. The cultivated characteristics of immobilization spawn of oyster mushroom TD300 during storage at $20-25{ }^{\circ} \mathrm{C}$ $\left(68.0-77.0{ }^{\circ} \mathrm{F}\right)$.

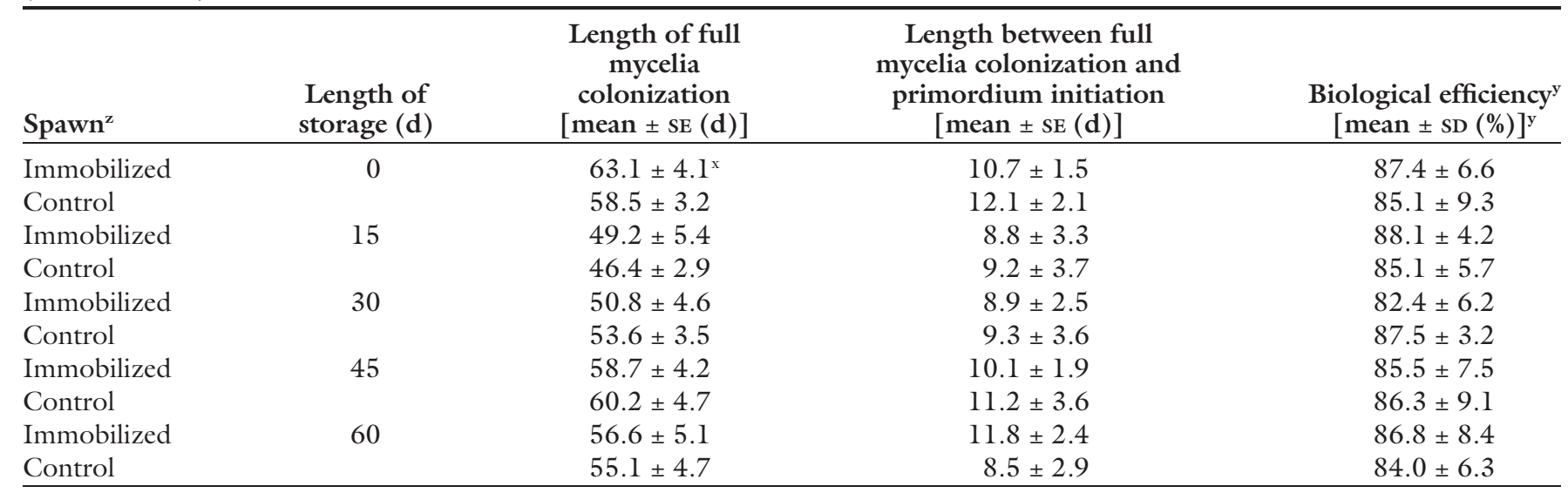

${ }^{\mathrm{z}}$ Immobilized is prepared by mixing pellets of TD 300 and carriers (cottonseed hull + corn core + wheat bran) on a ratio of $1: 8$ by weight. Control is fresh solid spawn grew on cottonseed hull with no storage.

yercentage of the fresh weight of harvested mushrooms over the dry weight of inoculation substrates.

${ }^{\mathrm{x} C}$ Columns without letters following means are not significantly different according to Duncan's multiple range test $(P<0.05)$.

prone to contamination. In this study, we developed an alternative method to immobilize mycelial pellets of liquid spawn based on carrier adsorption. The carriers are similar to those used in cultivation; it could effectively shorten the adaptation period and improve the growth rate after inoculation on cultivation substrates, as demonstrated by the immobilized spawn with cottonseed hull carrier in Table 1; pellets adsorbed by carriers are well spread, creating more inocula points. The immobilized spawn is convenient for storage and transportation and could grow on the carriers during storage and transportation; the storage period is more than $60 \mathrm{~d}$ in our study on oyster mushroom, a very attractive feature for the industry. Furthermore, the production can be run with simple and inexpensive machines. Finally, the supernatant of liquid spawn is nutritious and a potential source for food and medicine. Overall, our technique provides great benefits over the entrapment of alginate beads.

It was suggested that rhizobia in solid spawn of oyster mushroom helped to produce a higher yield of mineral and protein-rich oyster mushroom (Seneviratne et al., 2009). The bacteria could also act as biofertilizers in our immobilized spawn to achieve similar results.

\section{Literature cited}

Chang, S.T. 1999. World production of cultivated edible and medicinal mushrooms in 1997 with emphasis on Lentinus edodes (Berk.) Sing. in China. Intl. J. Medicinal Mushrooms 1:291-300.
Chinese Society of Plant Physiology. 1985. Manual plant physiology experiments. Shanghai Science and Technology Press, Shanghai, China.

El-Fakharany, E.M., B.M. Haroun, T.B. Ng, and E.R. Redwan. 2010. Oyster mushroom laccase inhibits hepatitis C virus entry into peripheral blood cells and hepatoma cells. Protein Pept. Lett. 17: 1031-1039.

Eyal, J. 1991. Mushroom mycelium grown in submerged culture-Potential food applications, p. 31-64. In: I. Goldberg and R. Williams (eds.). Biotechnology and food ingredients. Van Nostrand Reinhold, New York.

Friel, M.T. and A.J. McLoughlin. 1999. Immobilisation as a strategy to increase the ecological competence of liquid cultures of Agaricus bisporus in pasteurised compost. FEMS Microbiol. Ecol. 30:39-46.

Friel, M.T. and A.J. McLoughlin. 2000. Production of a liquid inoculum/spawn of Agaricus bisporus. Biotechnol. Lett. 22:351-354.

Gern, R.M., E. Wisbeck, J.R. Rampinelli, J.L. Ninow, and S.A. Furlan. 2008. Alternative medium for production of Pleurotus ostreatus biomass and potential antitumor polysaccharides. Bioresour. Technol. 99:76-82.

Humfeld, H. 1948. The production of mushroom mycelium (Agaricus campestris) in submerged culture. Science 107:373.

Kawai, G., H. Kobayashi, and Y. Fukushima. 1995. Liquid culture induces early fruiting in shiitake (Lentinula edodes). Mushroom Sci. 14:825-832.

Kerem, Z., D. Freisen, and Y. Hadar. 1992. Lignocellulose degradation during solid waste substrate fermentation:
Pleurotus ostreatus vs Phanerocheate chrysosporium. Appl. Environ. Microbiol. 68:1121-1127.

Kirchhoff, B. and J. Lelley. 1991. Investigations of shiitake [Lentinus edodes (Berk.) Sing.] bag-log cultivation to increase the yield in Germany, p. 509-516. In: M.J. Maher (ed.). Science and cultivation of edible fungi. Balkema, Rotterdam, The Netherlands.

Laniece, A. 1966. Production and use of liquid mushroom spawn. U.S. patent $3,286,399$. U.S. Patent and Trademark Office, Washington, DC.

Leatham, G.F. and T.J. Griffin. 1984. Adapting liquid spawn Lentinus edodes to oak wood. Appl. Microbiol. Biotechnol. 20:360-363.

Liu, Y., L. Wang, Y. Gao, Y. Qi, J. Shen, and L. Qiu. 2009. Studies on the liquid spawn solidification technique of Lentinus edodes. Edible Fungi China 28:16-17.

McLoughlin, A.J. 1994. Controlled release of immobilized cells as a strategy to regulate ecological competence of inocula. Adv. Biochem. Eng. Biotechnol. 59:1-45.

Miller, G.L. 1959. Use of dinitrosalicylic acid reagent for determination of reducing sugar. Anal. Chem. 31:426-428.

Miller, G.L., R. Blum, W.E. Glennon, and A.L. Burton. 1960. Measurement of carboxymethylcellulase activity. Anal. Biochem. 1:127-132.

Okamura-Matsui, T., T. Tomoda, S. Fukuda, and M. Ohsugi. 2003. Discovery of alcohol dehydrogenase from mushrooms and application to alcoholic beverages. J. Mol. Catalysis B Enzyme 23:133144. 


\section{Research Reports}

Pellinen, M., Y. Malkki, and A. Niskanen. 1987. Method of growing edible mushrooms. U.S. patent 4,637,163. U.S. Patent and Trademark Office, Washington, DC.

Qiu, L., Y. Li, Y. Liu, Y. Gao, Y. Qi, and J. Shen. 2010. Particle and naked RNA mycoviruses in industrially cultivated mushroom Pleurotus ostreatus in China. Fungal Biol. 114:507-513.

Rodríguez Pérez, S., N. García Oduardo, R.C. Bermúdez Savón, M. Fernández Boizán, and C. Augur. 2008. Decolourisation of mushroom farm wastewater by Pleurotus ostreatus. Biodegradation 19: 519-526.
Rosado, F.R., C. Kemmelmeier, and S.M. Da Costa. 2002. Alternative method of inoculum and spawn production for the cultivation of the edible brazilian mushroom Pleurotus ostreatoroseus Sing. J. Basic Microbiol. 42:37-44.

Seneviratne, G., G.A. Peyvast, J.A. Olfati, and A. Kariminia. 2009. Rhizobia as biofertilizers for mushroom cultivation. Curr. Sci. 96:1559.

Silveira, M.L., S.A. Furlan, and J.L. Ninow. 2008. Development of an alternative technology for the oyster mushroom production using liquid inoculum. Ciência e Tecnologia de Alimentos 28:858862.
Yan, K., H. Wang, X. Zhang, and H. Yu. 2009. Bioprocess of triphenylmethane dyes decolorization by Pleurotus ostreatus BP under solid-state cultivation. J. Microbiol. Biotechnol. 19:1421-1430.

Yan, Y. 1997. Study on esterase polyphenol oxidase and peroxidase of Pleurotus osteratus. J. Anhui Agr. Univ. 24:8892 .

Zhong, J.J. and Y.J. Tang. 2004. Submerged cultivation of medicinal mushrooms for production of valuable bioactive metabolites. Adv. Biochem. Eng. Biotechnol. 87:25-59. 